\title{
Traumatic thoracic ASIA A examinations and potential for clinical trials
}

James S. Harrop, MD

Thomas Jefferson University Hospital

Mitchell G. Maltenfort, PhD

Thomas Jefferson University Hospital

Fred H. Geisler, MD, PhD

Illinois Neuro-Spine Center

William Coleman, PhD

WPC Math

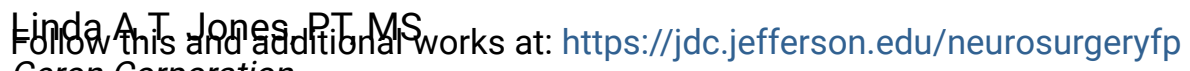
Geron Corporation

Part of the Medical Neurobiology Commons, Neurology Commons, and the Surgery Commons $\frac{\text { Let us know how access to this document benefits you }}{\text { See next page for additional authors }}$

\section{Recommended Citation}

Harrop, MD, James S.; Maltenfort, PhD, Mitchell G.; Geisler, MD, PhD, Fred H.; Coleman, PhD, William; Jones, PT, MS, Linda A.T.; Wirth, MD, Edward; and Vaccaro, MD, PhD, Alexander, "Traumatic thoracic ASIA A examinations and potential for clinical trials" (2009). Department of Neurosurgery Faculty Papers. Paper 5.

https://jdc.jefferson.edu/neurosurgeryfp/5

This Article is brought to you for free and open access by the Jefferson Digital Commons. The Jefferson Digital Commons is a service of Thomas Jefferson University's Center for Teaching and Learning (CTL). The Commons is a showcase for Jefferson books and journals, peer-reviewed scholarly publications, unique historical collections from the University archives, and teaching tools. The Jefferson Digital Commons allows researchers and interested readers anywhere in the world to learn about and keep up to date with Jefferson scholarship. This article has been accepted for inclusion in Department of Neurosurgery Faculty Papers by an authorized administrator of the Jefferson Digital Commons. For more information, please contact: JeffersonDigitalCommons@jefferson.edu. 


\section{Authors}

James S. Harrop, MD; Mitchell G. Maltenfort, PhD; Fred H. Geisler, MD, PhD; William Coleman, PhD; Linda A.T. Jones, PT, MS; Edward Wirth, MD; and Alexander Vaccaro, MD, PhD 


\title{
As submitted to:
}

\author{
Spine
}

And later published as:

\section{Volume 34, Issue 23, November 2009, Pages 2525-2529}

\section{DOI: 10.1097/BRS.0b013e3181bd1402}

\section{"Traumatic Thoracic ASIA A Examinations and Potential for Clinical Trials"}

\author{
James S. Harrop, MD*† \\ Mitchell Gil Maltenfort, PhD* \\ Fred H. Geisler, MD, PhD \\ William Coleman, $\mathrm{PhD} \mathscr{I}$ \\ Linda A.T. Jones, PT, MS $\|$ \\ Edward Wirth, MD• \\ Alexander Vaccaro, $\mathrm{MD}, \mathrm{PhD}^{*} *$
* Department of Neurological Surgery
Thomas Jefferson University Hospital 909 Walnut Street
Philadelphia, PA 19107
$\dagger$ Department of Orthopedic Surgery
Thomas Jefferson University Hospital The Rothman Institute 925 Chestnut St. Philadelphia, PA 19107
†llinois Neuro-Spine Center, 2020 Ogden Avenue Aurora, IL 60504, USA
ITWPC Math Buffalo, NY 14222
|| Geron Corporation 1950 Tincup Court Boulder, CO 80305
- Geron Corporation 230 Constitution Drive




\section{Corresponding Author:}

James S. Harrop, M.D.

Department of Neurological Surgery

Thomas Jefferson University Hospital

909 Walnut Street

Philadelphia, PA 19107

James.harrop@jefferson.edu

Tel: $215-955-7959$

Fax: 215-503-9170

Keywords: Spinal cord injury, recovery, ASIA, sensation, thoracic and thoracolumbar 


\section{ABSTRACT}

Study Design: Retrospective review of prospective database

Objectives: To define the variability of neurologic examination and recovery after nonpenetrating complete thoracic spinal cord injuries (ASIA A).

Background Data: Neurologic examinations after SCI can be difficult and inconsistent. Unlike cervical SCI patients, alterations in thoracic (below T1) complete SCI (ASIA A - based on the ASIA Impairment Scale [AIS]) patients' exams are based only on sensory testing, thus changes in the neurological level (NL) are determined only by sensory changes.

Methods: A retrospective review of the placebo control patients in a multicenter prospective database utilized for the pharmacologic trial of Sygen. Patients were included if they had a complete thoracic SCI on initial evaluation, with completed ASIA examinations at follow-up weeks 4, 8, 16, 26 and 52. Specifically, pin prick (PP) and light touch (LT) were assessed and the absolute change was calculated as the number of spinal levels at a given observation time. Results 3165 patients were initially screened for the Sygen clinical trial, of which 57 were the control placebo patients used in this analysis. Alterations from the baseline exam (PP and LT) were fairly consistent and the median change/recovery in neurologic examination was one spinal level. Across all observations post-baseline, the average change for PP was $1.48+/-0.13$ (mean +/- SE), and for LT, $1.40+/-0.13$. There were equal proportions of directional changes (none, improved, lost).

\section{Conclusions:}

Changes in a thoracic complete (ASIA A) SCI patient ASIA examination as measured through sensory modalities (PP/LT) are fairly uncommon. The overall examination had only 1-2 level 
variability across patients, indicating minimal change in the sensory exam over the follow-up period. Stability in the ASIA examination as measured through sensory modalities has thus been demonstrated over time, making it an excellent tool to monitor changes in neurologic function. 


\section{INTRODUCTION}

Traumatic spinal cord injuries (SCI) are devastating events that typically affect a younger population, resulting in a significant loss of economic and social productivity. Determining the extent of injury and overall prognosis after a spinal cord injury is a complex process and is presently assessed through the neurologic examination. Unfortunately, in thoracic SCI patients the variability and consistency of these neurologic examinations are unknown, particularly due to the dependence on the sensory examination. Patients with injuries from T2-T10 are presently being targeted for pharmacologic and surgical interventions in future potential SCI therapies, because the distance between the last functioning motor units (T1 level) and the site of neurologic injury decreases their potential for losing motor function. The T10 cut off increases the chance of a pure spinal cord lesion, avoiding the conus medullaris and cauda equina.

The International Standards for Classification of Spinal Cord Injury (commonly known as the American Spinal Injury Association [ASIA] exam) examination is a validated neurologic evaluation tool utilized for baseline and serial examinations following spinal cord injury. ${ }^{1,2}$ This examination has been successfully utilized in multiple SCI trials ${ }^{3-5}$; however, its variability in isolated thoracic SCI is unknown. Unlike the cervical spinal cord injuries where the exact neurological level (NL) can be confirmed by the physical examination through both a motor and sensory level, the thoracic ASIA level (below T1) is defined by only the sensory portion of the examination. This article, therefore, analyzes a large population of complete thoracic SCI patients (ASIA A) to assess the variability of the thoracic ASIA examination.

\section{METHODS}


This is a retrospective review of the data obtained from the Sygen pharmaceutical trial for spinal cord injured patients specifically analyzing the placebo control patients who did not receive the study medication (Sygen). ${ }^{6}$ The Sygen study was a prospective, double blind, randomized, stratified, multicenter trial of the influence of a GM1 ganglioside on neurologic recovery after SCI. Full details of the trial's design, recruitment and enrollment have been previously published. ${ }^{6,7}$ As part of the study, patients were excluded for the presence of: penetrating gunshot wounds, spinal cord transection, significant cauda equina, brachial or lumbosacral plexus, or peripheral nerve injury.

This particular analysis consisted of a retrospective review of the Sygen database to specifically analyze the variability of the thoracic ASIA examination and definition of the NL in complete motor and sensory spinal cord injury (ASIA A) patients. All examiners for Sygen were trained and reliability assessed. ${ }^{6,7}$ No patients had voluntary lower extremity movement, and were graded $0 / 5$ out of a 6 grade point system. Sensory modalities, pin prick (PP) and light touch (LT), were assessed as the highest spinal level at which at least one dermatome (left or right) showed absent or abnormal response to stimulus. Thus the neurologic level of injury was the most caudal normally innervated dermatome. The complete ASIA examination including PP and LT levels was assessed at baseline (BAS) and at 4, 8, 16, 26 and 52 weeks. The absolute change in PP or LT was calculated as the number of spinal levels from baseline (up or down) at a given observation time. Averaging positive and negative changes (movement up and down the spinal cord) would actually be misleading, as positive and negative changes cancel each other out in calculation of the mean. 


\section{$\underline{\text { RESULTS }}$}

3165 patients were initially screened for inclusion into the prospective Sygen study, of which 797 acute spinal cord injuries (ASIA A) met the inclusion criteria and were successfully enrolled. This consisted of 516 cervical ASIA A patients, including 170 thoracic ASIA A patients. 138 of these 170 thoracic motor and sensory complete or ASIA A patients had documented ASIA examinations at: baseline (time of injury), 4 weeks, 8 weeks, 16 weeks, 26 weeks and 52 weeks post injury. However, only 135 of the 138 had completed sensory examinations consisting of both pin prick and light touch scores and thus were included in the final analysis. 51 were placebo control patients with injuries in the T2-T10 range (the analysis population for this article), separated by level in figure 1, tables 1 and 2 .

Transitions or alterations from the baseline examination were fairly consistent for both PP and LT sensory modalities. The median movement was one spinal level in either a caudal or cranial direction, and $75 \%$ of patients were within two spinal levels. Across all observations post-baseline, the average movement for PP was $1.48+/-0.13$ (mean +/- SE), and for LT, 1.40 +/-0.13.( tables 1 and 2) For weeks 4-26, the distribution of positional changes was approximately equal; at week 52 , more than $70 \%$ of the sensory levels were at their baseline. The majority of measurements illustrated either no change from baseline or a shift of less than 3 levels. (figure 2)

\section{$\underline{\text { DISCUSSION }}$}

There are approximately 10,000 spinal cord injury (SCI) patients annually in North America. ${ }^{8}$ Attempts to maximize the potential for neurologic recovery after an acute SCI trauma have been fraught with numerous barriers. In recent years, fortunately, there have been significant advances through laboratory investigations in the understanding of the pathogenesis 
and treatment of SCI. ${ }^{9-13}$ However, when applied in clinical translational trials, these laboratory advances have not yielded the same clinical or therapeutic benefits. ${ }^{5-7,14-17}$ One difficulty clinically has been the limited ability to measure and interpret therapeutic effects of these treatment modalities.

In order to differentiate subtle clinical benefits afforded by pharmaceutical and translational clinical trials, we must have a comprehensive understanding of the natural history of the SCI disease process. This information will facilitate an accurate design of translational protocols and the ability to differentiate clinically significant findings. For example, patients with incomplete SCI (partial motor of sensory function below level of injury) have the greatest potential to spontaneously recover motor function. This variability of neurologic recovery will unduly influence clinical trials for acute SCI; trials will therefore likely require neurologically complete injuries (ASIA A) with their more consistent recovery pattern as well as for safety reasons.

The neurologic level (NL) of injury defined by the ASIA exam localizes functioning and injured motor neurons and sensory fibers in relation to the spinal cord anatomy. ${ }^{1,18}$ The ASIA examination has been validated in terms of its ability to quantify the degree of patient's neurologic injury as well as potential for further neurologic recovery. ${ }^{19}$ Waters et al illustrated that the absence of sacral sparing of sensation is the most reliable and clinically useful definition of a complete spinal cord injury and is the premise of the ASIA A (complete) definition. ${ }^{20}$ Thoracic ASIA A SCI patients, however, are the most difficult to clinically assess changes since their ASIA level has neither discrete anatomic landmarks nor concurrent motor nerve roots to verify the level. 
Although the ASIA examination has been validated in SCI populations, there has been limited evaluation of the complete thoracic ASIA A SCI patients due to their small numbers. Savic et al performed a prospective observational study on the inter-rater reliability of motor and sensory examination performed according to the ASIA standards in 45 SCI patients. The authors concluded there was a very good level of agreement between examiners. ${ }^{21}$ However, this study excluded patients whose ASIA level was defined based solely on sensation. (rostral to C4 or T2L1) In this present analysis a large number of ASIA examinations on complete thoracic ASIA A patients (figure 1) were reviewed to assess the reliability of the examination in terms of its consistency during repeated evaluations through a one year period. Despite the numerous adverse influences on obtaining an accurate physical examination in thoracic ASIA A patients, we found the thoracic ASIA level of injury based on the sensory evaluation (T2-10) to be a very stable test to quantify and follow neurologic function. In fact, the median change of ASIA examination over this one year period was only a single thoracic spinal level in either a rostral or caudal direction. (Figures 3 and 4) Illustrated throughout this series was that not only were the patients' neurologic examinations stable, but also that there was no significant change in the patients' overall neurologic function for a one year period. Across all observations postbaseline, the average movement for pinprick (PP) was $1.48+/-0.13$ (mean +/- SE), and for lighttouch (LT), $1.40+/-0.13$. (Figure1) (mean +/- SE),

Furthermore, when analyzing the percentage of patients with neurologic change, both the pinprick and light touch sensations yielded similar results.(Figures 3 and 4) Approximately one third of patients either neurologically improved, worsened or remained the same within one thoracic spinal level (figure 4). The spontaneous recovery of only a single thoracic sensory level 
can be correlated to the cervical SCI data, which shows that there is the potential for single level of return juxtaposed to the level of injury. ${ }^{22-24}$

Interestingly, the greatest variability in the thoracic ASIA A examination occurred during the first 4 week period after injury. This is most likely attributed to the early influence of surgical intervention (positive or negative), difficulty in precisely localizing the level due to a patient population in significant pain, sedation and being in an ICU setting.(Figure 2) However, examinations after the four week period illustrated remarkably similar and consistent results. This stabilization of the examination might be the result of the ability to obtain consistent neurologic assessments since the patient is in a more controlled environment. However, the multitude of consistent ASIA examinations further suggests that there is a plateau of neurologic recovery, thus inferring no further neurologic improvement after the four week period. Unfortunately, even the greatest degree of neurologic recovery occurred in only one third of the patients and was still only one thoracic spinal level. (figures 3,4) When analyzing the data by quartiles to view the degree of change in the ranges farthest from the median, even this variability was less than 5 segments and with time decreased significantly (fig 4 A and B)

Therefore, the ASIA examination identifies severely injured patients (ASIA A) who may benefit from inclusion in SCI clinical trials. The present study illustrates that thoracic (T2-10) ASIA A patients are excellent candidates for clinical trials in that the ASIA examination is stable enough to be sensitive to neurologic small changes. In addition, this patient group had limited spontaneous neurologic recovery during the one year follow-up period. Burns et al retrospectively reviewed the spontaneous motor recovery in 103 ASIA A patients at one year from injury and found similar results. Overall only 6.2\% (5/81) of (ASIA A) converted to ASIA B status and no patient exhibited any motor recovery (ASIA C or D). ${ }^{25}$ The authors concluded 
that the ASIA examination at 48 hrs provides "a subset of patients with a negligible chance for motor recovery who would be suitable candidates for future clinical trials of invasive treatments." 25

\section{CONCLUSION}

Changes in a thoracic complete (ASIA A) SCI patient examination as measured through sensory modalities (PP/LT) are fairly common in the first four weeks post-injury. However, the overall thoracic ASIA A examinations had only 1-2 level variability across patients over the one year follow-up period. Therefore, this is an excellent tool and patient population to monitor changes in neurologic function for potential SCI intervention. 


\begin{tabular}{|l|l|l|l|l|l|l|}
\hline \multirow{2}{*}{ Week } & \multicolumn{2}{|l|}{ Caudal PP } & \multicolumn{2}{l|}{ No Change } & \multicolumn{2}{l|}{ Rostral PP } \\
\cline { 2 - 7 } & Mean & SE & Mean & SE & Mean & SE \\
\hline 4 & $35.85 \%$ & $6.53 \%$ & $33.96 \%$ & $6.44 \%$ & $30.19 \%$ & $6.25 \%$ \\
\hline 8 & $34.00 \%$ & $6.57 \%$ & $32.00 \%$ & $6.47 \%$ & $34.00 \%$ & $6.57 \%$ \\
\hline 16 & $32.69 \%$ & $6.70 \%$ & $30.77 \%$ & $6.59 \%$ & $36.54 \%$ & $6.88 \%$ \\
\hline 26 & $38.78 \%$ & $6.89 \%$ & $40.82 \%$ & $6.95 \%$ & $20.41 \%$ & $5.70 \%$ \\
\hline 52 & $12.96 \%$ & $4.75 \%$ & $74.07 \%$ & $6.20 \%$ & $12.96 \%$ & $4.75 \%$ \\
\hline
\end{tabular}

Table I: distribution of directional changes over time (PP)

\begin{tabular}{|l|l|l|l|l|l|l|}
\hline \multirow{2}{*}{ Week } & \multicolumn{2}{|l|}{ Caudal LT } & \multicolumn{2}{l|}{ No Change } & \multicolumn{2}{l|}{ Rostral LT } \\
\cline { 2 - 7 } & Mean & SE & Mean & SE & Mean & SE \\
\hline 4 & $36.73 \%$ & $6.82 \%$ & $38.78 \%$ & $6.89 \%$ & $24.49 \%$ & $6.08 \%$ \\
\hline 8 & $38.46 \%$ & $6.88 \%$ & $38.46 \%$ & $6.88 \%$ & $23.08 \%$ & $5.96 \%$ \\
\hline 16 & $41.51 \%$ & $6.77 \%$ & $37.74 \%$ & $6.66 \%$ & $20.75 \%$ & $5.57 \%$ \\
\hline 26 & $42.86 \%$ & $6.86 \%$ & $30.61 \%$ & $6.39 \%$ & $26.53 \%$ & $6.12 \%$ \\
\hline 52 & $10.91 \%$ & $4.45 \%$ & $70.91 \%$ & $6.49 \%$ & $18.18 \%$ & $5.51 \%$ \\
\hline
\end{tabular}

Table II: distribution of directional changes over time (LT) 


\section{REFERENCES}

1. Cohen ME, Ditunno JF, Jr., Donovan WH, Maynard FM, Jr.: A test of the 1992 International Standards for Neurological and Functional Classification of Spinal Cord Injury. Spinal Cord 36:554-560, 1998.

2. Marino RJ, Ditunno JF, Jr., Donovan WH, Maynard F, Jr.: Neurologic recovery after traumatic spinal cord injury: data from the Model Spinal Cord Injury Systems. Arch Phys Med Rehabil 80:1391-1396, 1999.

3. Bracken MB, Shepard MJ, Holford TR, Leo-Summers L, Aldrich EF, Fazl M, Fehlings M, Herr DL, Hitchon PW, Marshall LF, Nockels RP, Pascale V, Perot PL, Jr., Piepmeier J, Sonntag VK, Wagner F, Wilberger JE, Winn HR, Young W: Administration of methylprednisolone for 24 or 48 hours or tirilazad mesylate for 48 hours in the treatment of acute spinal cord injury. Results of the Third National Acute Spinal Cord Injury Randomized Controlled Trial. National Acute Spinal Cord Injury Study. Jama 277:15971604, 1997.

4. Fehlings MG, Bracken MB: Summary statement: the Sygen(GM-1 ganglioside) clinical trial in acute spinal cord injury. Spine 26:S99-100, 2001.

5. Young W, Bracken MB: The Second National Acute Spinal Cord Injury Study. J Neurotrauma 9 Suppl 1:S397-405, 1992.

6. Geisler FH, Coleman WP, Grieco G, Poonian D: The Sygen multicenter acute spinal cord injury study. Spine 26:S87-98, 2001.

7. Geisler FH, Coleman WP, Grieco G, Poonian D: Measurements and recovery patterns in a multicenter study of acute spinal cord injury. Spine 26:S68-86, 2001.

8. Ho CH, Wuermser LA, Priebe MM, Chiodo AE, Scelza WM, Kirshblum SC: Spinal cord injury medicine. 1. Epidemiology and classification. Arch Phys Med Rehabil 88:S4954, 2007.

9. Levene HB, Mohamed FB, Faro SH, Seshadri AB, Loftus CM, Tuma RF, Jallo JI: Small mammal MRI imaging in spinal cord injury: a novel practical technique for using a $1.5 \mathrm{~T}$ MRI. J Neurosci Methods 172:245-249, 2008.

10. Pinzon A, Marcillo A, Quintana A, Stamler S, Bunge MB, Bramlett HM, Dietrich WD: A re-assessment of minocycline as a neuroprotective agent in a rat spinal cord contusion model. Brain Res, 2008.

11. Rabinowitz RS, Eck JC, Harper CM, Jr., Larson DR, Jimenez MA, Parisi JE, Friedman JA, Yaszemski MJ, Currier BL: Urgent surgical decompression compared to methylprednisolone for the treatment of acute spinal cord injury: a randomized prospective study in beagle dogs. Spine 33:2260-2268, 2008.

12. Shields LB, Zhang YP, Burke DA, Gray R, Shields CB: Benefit of chondroitinase ABC on sensory axon regeneration in a laceration model of spinal cord injury in the rat. Surg Neurol 69:568-577; discussion 577, 2008.

13. Suzuki K, Kazui T, Terada H, Umemura K, Ikeda Y, Bashar AH, Yamashita K, Washiyama N, Suzuki T, Ohkura K, Yasuike J: Experimental study on the protective effects of edaravone against ischemic spinal cord injury. J Thorac Cardiovasc Surg 130:1586-1592, 2005. 
14. Bracken MB: Treatment of acute spinal cord injury with methylprednisolone: results of a multicenter, randomized clinical trial. J Neurotrauma 8 Suppl 1:S47-50; discussion S5142, 1991.

15. Bracken MB: Pharmacological treatment of acute spinal cord injury: current status and future projects. J Emerg Med 11 Suppl 1:43-48, 1993.

16. Bracken MB, Shepard MJ, Collins WF, Jr., Holford TR, Baskin DS, Eisenberg HM, Flamm E, Leo-Summers L, Maroon JC, Marshall LF, et al.: Methylprednisolone or naloxone treatment after acute spinal cord injury: 1-year follow-up data. Results of the second National Acute Spinal Cord Injury Study. J Neurosurg 76:23-31, 1992.

17. Holford TR, Bracken MB: A model for estimating level and net severity of spinal cord injuries. Stat Med 11:1171-1186, 1992.

18. Maynard FM, Jr., Bracken MB, Creasey G, Ditunno JF, Jr., Donovan WH, Ducker TB, Garber SL, Marino RJ, Stover SL, Tator CH, Waters RL, Wilberger JE, Young W: International Standards for Neurological and Functional Classification of Spinal Cord Injury. American Spinal Injury Association. Spinal Cord 35:266-274, 1997.

19. El Masry WS, Tsubo M, Katoh S, El Miligui YH, Khan A: Validation of the American Spinal Injury Association (ASIA) motor score and the National Acute Spinal Cord Injury Study (NASCIS) motor score. Spine 21:614-619, 1996.

20. Waters RL, Adkins RH, Yakura JS: Definition of complete spinal cord injury. Paraplegia 29:573-581, 1991.

21. Savic G, Bergstrom EM, Frankel HL, Jamous MA, Jones PW: Inter-rater reliability of motor and sensory examinations performed according to American Spinal Injury Association standards. Spinal Cord 45:444-451, 2007.

22. Mange KC, Ditunno JF, Jr., Herbison GJ, Jaweed MM: Recovery of strength at the zone of injury in motor complete and motor incomplete cervical spinal cord injured patients. Arch Phys Med Rehabil 71:562-565, 1990.

23. Mange KC, Marino RJ, Gregory PC, Herbison GJ, Ditunno JF, Jr.: Course of motor recovery in the zone of partial preservation in spinal cord injury. Arch Phys Med Rehabil 73:437-441, 1992.

24. Wu L, Marino RJ, Herbison GJ, Ditunno JF, Jr.: Recovery of zero-grade muscles in the zone of partial preservation in motor complete quadriplegia. Arch Phys Med Rehabil 73:40-43, 1992.

25. Burns AS, Lee BS, Ditunno JF, Jr., Tessler A: Patient selection for clinical trials: the reliability of the early spinal cord injury examination. J Neurotrauma 20:477-482, 2003. 